\title{
Bilateral paramedian thalamic and mesencephalic infarcts after basilar tip aneurysm coiling: role of the artery of Percheron
}

\author{
L. Rangel-Castilla; J. Gasco; B. Thompson y P. Salinas
}

Division of Neurosurgery. University of Texas Medical Branch (UTMB). Galveston. Texas.

\section{Summary}

Aneurysm embolization using Guglielmi detachable coils (GDC) is gaining acceptance as a viable alternative for surgery in the treatment of aneurysms. Recent reports describe a significant rate of thromboembolic complications. Thalamic and midbrain blood supply can arise from complex anatomical variations. The rare variation: "artery of Percheron", is a solitary arterial trunk arising from one of the proximal segments of a posterior cerebral artery and supplies the paramedian thalami and rostral midbrain bilaterally. We describe a patient that underwent elective endovascular treatment for a basilar tip aneurysm using GDC and stents in each PCA; 12 hours later patient was comatose and not following commands. Sequential magnetic resonance imaging (MRI) of brain showed bilateral paramedian thalamic and mesencephalic infarcts presumably secondary to artery of Percheron occlusion. Thromboembolic event related to the use of the GDC embolization and stents is a rare clinical sequelae, but catastrophic. The use of antiplatelets agents should be reinforced in the scenario. When bilateral medial thalamic and midbrain infarcts are found, occlusion of the artery of Percheron should be considered. Angiography may not b helpful and lack of visualization of the artery does not exclude its presence. In this case the MRI findings confirmed the presence of the infarction based on the anatomical distribution.

KEY WORDS: Endovascular treatment. Coiling. Basilar tip aneurysm. Bilateral paramedian thalamic and mesencephalic infarcts. Artery of Percheron.

Infarto talámico paramedial bilateral y mesencefálico después del tratamiento endovascular de un aneurisma de la punta de la arteria basilar: rol de la arteria de Percheron

Recibido: 4-09-08. Aceptado: 15-11.08
Resumen

La técnica endovascular para el manejo de aneurismas está ganando auge como una alternativa a la cirugía abierta. Sin embargo, se han descrito diferentes complicaciones tromboembólicas relacionadas con esta modalidad. El flujo sanguíneo al tálamo y al mesencéfalo puede surgir de variaciones anatómicas complejas. La variación infrecuente: "arteria de Percheron", es una rama arterial solitaria que se origina del segmento proximal de una de la arterias cerebrales posteriores.

Presentamos un paciente que tuvo un procedimiento endovascular electivo para el tratamiento de un aneurisma de la punta de la arteria basilar; 12 horas después del procedimiento, el paciente estaba clínicamente en coma profundo. La resonancia magnética $(\mathrm{RM})$ cerebral mostró infartos talámicos paramediales bilaterales y mesencefálicos, compatible con la oclusión de la arteria de Percheron.

Los eventos tromboembólicos relacionados con el uso de embolización con coil y stents es una rara pero catastrófica secuela. El uso de agentes antiplaquetarios se debe de recomendar en este tipo de situaciones. Cuando existen infartos talámicos paramediales bilaterales $\mathbf{y}$ mesencefálicos, la oclusión de la arteria de Percheron se debe de tener en mente. La angiografía puede no ser de mucha utilidad y la falta de visualización de la arteria no excluye su presencia. En este caso los hallazgos en la RM cerebral confirman la presencia de un infarto basado en la distribución anatómica de la arteria de Percheron.

PALABRAS CLAVE: Endovascular. Coil. Aneurisma cerebral. Arteria basilar. Infarto talámico paramediano bilateral y mesencefálico. Arteria de Percheron

Introduction

Endovascular embolization of cerebral aneurysms has evolved rapidly worldwide in recent years, and has increased in popularity at the expense of surgical clipping; how- 


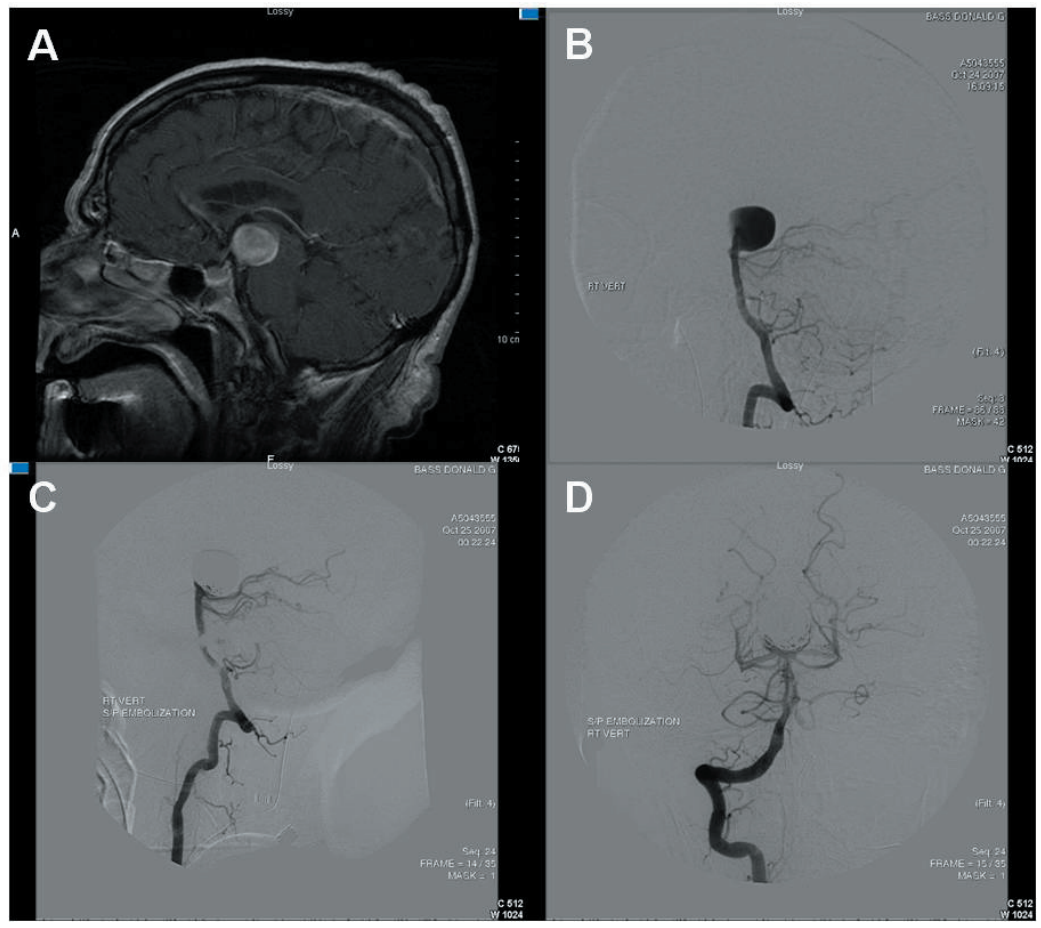

Figure 1. A. Sagittal T1W1 MRI with contrast showing a $24 \times 20 \mathrm{~mm}$ basilar tip aneurysm. $B$. Lateral view of right vertebral artery injection showing basilar tip aneurysm before coiling. $C$ and D. Lateral and AP views of right vertebral artery angiography showing basilar tip aneurysm after successfully coiling with all major basilar artery branches presumably patent and no evidence of thrombosis compared with pre-coiling images.

ever, both methods have inherent risks. It has been described that embolization with coils is the preferred treatment for patients with ruptured basilar bifurcation aneurysms. There is evidence that in a healthy patient with ruptured aneurysms of either anterior or posterior circulation in which both surgical clipping and endovascular treatment are viable options, coiling is associated with a better outcome ${ }^{16}$. Aneurysm embolization using Guglielmi detachable coils (GDC) is gaining acceptance as a viable alternative to surgery. Although, recent reports describe a significant rate of symptomatic thromboembolic complications with GDC use, many of the neurological deficits found are transient and most of are caused by catheter manipulation, especially in the case of the balloon-assisted technique ${ }^{13}$. Thromboembolic events related to the use of GDC embolization are relatively common $^{14}$, occurring in up to $28 \%$ of GDC embolization patients and resulted in persistent deficit in $5 \%$ of patients in one series ${ }^{8}$. Clinical sequelae are rare, but the high rate of occurrence suggests that alteration in the technique, such as the addition of antiplatelets agents, should be considered ${ }^{12}$. The use of diffusion weighted (DW) magnetic resonance imaging (MRI) is being used to determine the frequency and radiological appearance of thromboembolic events during embolization. Some authors have reported an incidence of acute ischemic lesion in only $10 \%$ of patients that underwent endovascular treatment based on DW and fluid-attenuated inversion recovery (FLAIR) ${ }^{1}$. Other authors found new hyperintense lesions in 61 to $69 \%$ of patients based on DW images $^{14}$.

Acute ischemic strokes in the brainstem secondary to vascular occlusion arising from the posterior circulation are catastrophic and carry a poor prognosis. Thalami and midbrain receive their blood supply from both anterior and posterior circulation, and several variations in this supply are known to exist. The posterior circulation usually supplies the medial aspects of the thalami and midbrain via branches arising from P1 segments and the lateral and superior aspect with branches arising from P2 segments of the posterior cerebral arteries (PCAs). Percheron studied the variations of this arterial supply and its distributions and described three different types of supply origins from P1 segments. In the second variation described by Percheron, there is a common trunk arising from one of the $\mathrm{P} 1$ segments providing bilateral distribution. Occlusion of this trunk results in bilateral infractions in the middle aspects of thalami and brain stem. We describe clinical and MRI findings in a patient who developed infarctions in the typical distribution of the artery of Percheron after endovascular embolization of a basilar artery aneurysm.

\section{Case report}

We present a 71 year old male who had a history diabetes mellitus and hypertension, was diagnosed with basilar tip aneurysm $(13 \times 10 \mathrm{~mm})$ in July 2003 by computer tomography (CT) angiogram. At time of diagnosis, patient refused treatment and was lost to follow-up. Patient returned to the ER in October 2007 with sudden onset of occipital headache, dizziness, and blurred vision. On examination, he was found to be neurological intact. Magnetic resonance imaging showed a basilar tip aneurysm (Fig 1A) 


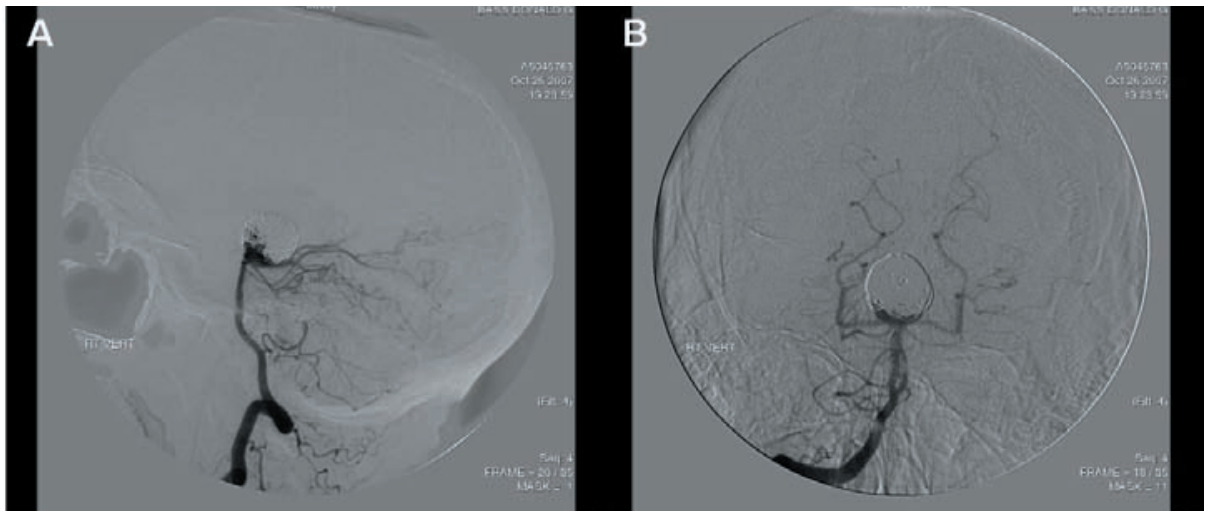

Figure 2. Lateral and AP views of right vertebral artery angiography showing basilar tip aneurysm previously coiled with all major basilar artery branches patent, with no evidence of vasospasm.

(24 x $20 \mathrm{~mm}$ ) with mild compression on midbrain, without hemorrhage or ischemic changes in the midbrain or thalamus
(Fig 3A and B). Cerebral angiography (Fig 1B) and coiling of the aneurysm were performed using 2 and $3 \mathrm{~mm}$ GDC,

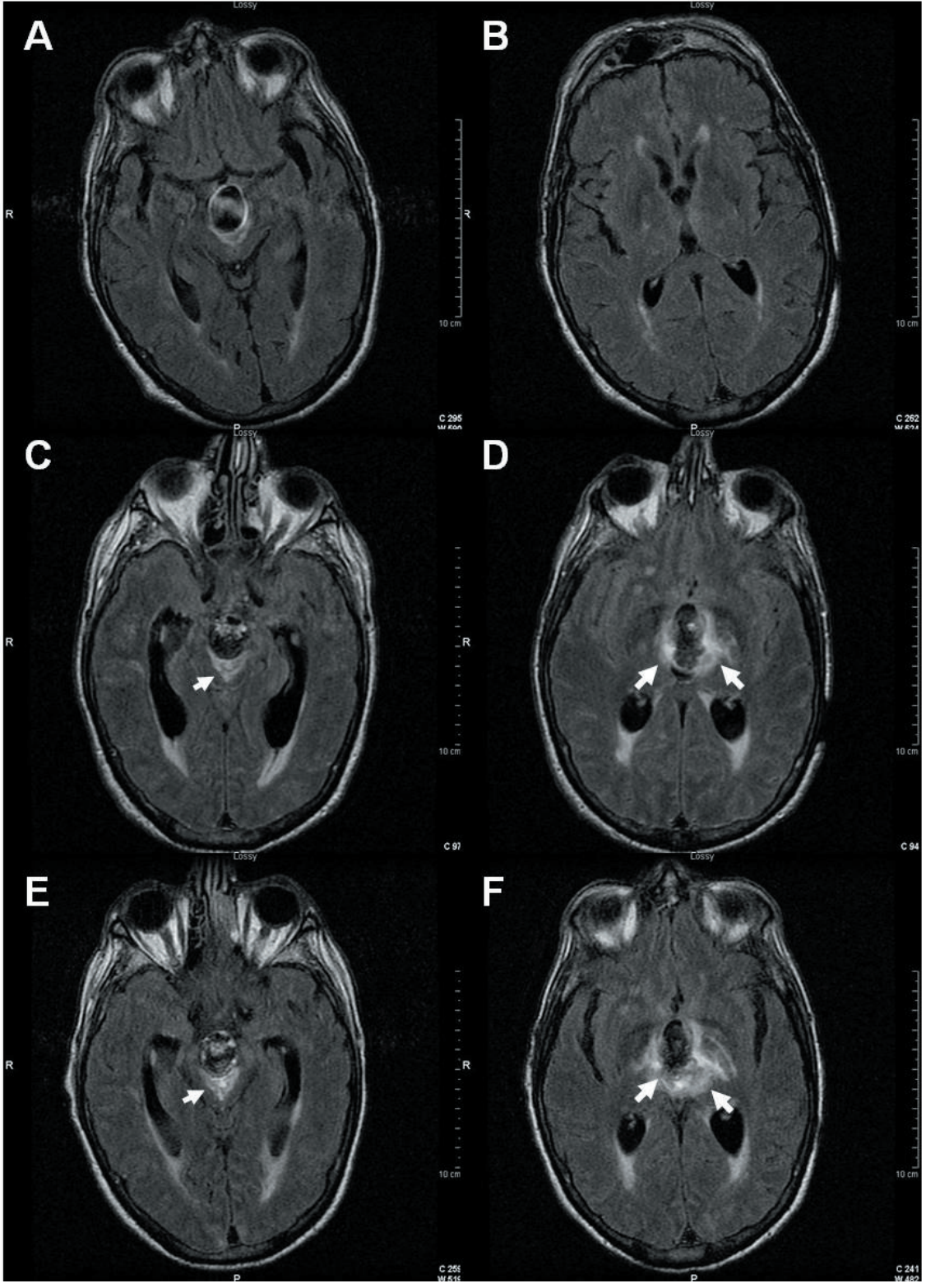

Figure 3. Axial T2WI Flair images of before (A and B) coiling showing no hyperintense changes. Six days ( $C$ and D) after coiling MRI demonstrated obvious hyperintense changes on midbrain (C, small arrow) and bilateral paramedian thalamus (D, big arrows) compatible with strokes. Eleven (E and F) days after coiling MRI showing enlargement of the hyperintense areas in midbrain (E, small arrow) and paramedian thalamus (F, big arrows). 
at this point patient was receiving $75 \mathrm{mg}$ of copidogrel daily. During the procedure a stent was deployed in the left and right (PCA), post embolization angiogram showed near complete embolization with contrast stasis, all major vessels were patent (Fig. 1C and D). Patient was subsequently transferred to the intensive care unit. Twelve hours after the procedure, the patient became lethargic, but continue to follow commands on both sides, moving the left side more than the right side. CT of the head was performed and showed no hemorrhage, no stroke, and no hydrocephalus. Repeat angiogram was performed and showed good flow in major vessels including both PCAs. No radiographic signs of vasospasm were observed (Fig 2A and B). Patient deteriorated over the next 24 hours, became comatose, and regressed to bilateral localization to painful stimuli. Pupil reactivity was sluggish, but symmetric. Eventually the patient was intubated to protect airway. Repeat MRI of brain $48 \mathrm{hrs}$ post coiling showed a small right occipital hyperintense area on $\mathrm{T} 2 \mathrm{~W} 1$, consistent with acute ischemic stroke and a slight increase mass effect on the midbrain, patient was still receiving copidogrel. Triple H therapy was started with no clinical improvement. Repeat MRI of brain 6 (Fig 3C and D), and 11 days (Fig 3E and F) after coiling showed obvious hyperintense areas on $\mathrm{T} 2 \mathrm{~W} 1$ in the midbrain, bilateral hypothalamus, and bilateral paramedian thalamus. Patient underwent tracheostomy and gastrostomy. Neurological exam at the time of discharge consisted of an obtunded patient that opened his eyes to painful stimuli had symmetric and bilaterally reactive pupils, localizing to pain on the left side and withdrawing to pain on the right side.

\section{Discussion}

Despite experience and technological improvements, endovascular treatment of intracranial aneurysm still has inherent risks, such as thromboembolism, intra and postprocedure aneurysm perforation, coil migration and parent vessel injury or occlusion. Risk of thromboembolism is 8.4 to $17.6 \%$ in previous reports ${ }^{6,15}$. Coiling has come to be regarded as safe and effective procedure for the treatment of basilar tip aneurysm ${ }^{7}$. During the coiling of this type of aneurysm, a large amount of attention must be focused on maintaining the patency of the various vascular branches originating from the basilar artery, including perforating arteries, PCA and its variants. One of the less common variants is a common trunk arising from P1, called artery of Percheron.

\section{Artery of Percheron}

The posterior communicating artery contributes to thalamic blood supply in $60 \%$ of humans. This is accomplished by a, well characterized artery, the polar artery. Its territory comprises the rostral pole of the lateral region up to the mamillothalamic fasciculus. Percheron described three possible variations involving the paramedian thalamicmesencephalic arterial supply: 1) small branches arising from both P1 segments, 2) asymmetrical common trunk arising from a $\mathrm{P} 1$ segment (this variation is called the artery of Percheron) (Fig 4), 3) an arterial arcade emanating from an artery bridging the two P1 segments ${ }^{9-11}$. The basilar communicating artery (or mesencephalic artery) often gives off one than two paramedian thalami arteries. The paramedian territory has a variable extent, including the polar territory when the polar artery does not exist. The paramedian artery arises from the contralateral basilar communicating artery as frequently as it does a single artery. One basilar communicating artery may have a very extensive bilateral territory. The mesencephalic-diencephalic junction arterial supply defines the size and location of the ischemic damage. Perforating arteries arising from both P1 segments of the PCA supply primarily the hypothalamus, medial ventral thalami and subthalamic-mesencephalic junction. (Fig 4).

Presentation of the current case is typical of a vascular insult in the above described anatomic region. Patients with paramedian thalamic ischemia and infarction are often obtunded, comatose, cranial nerve III may be involved, may associated hemiplegia or hemisensory loss may occur. Depending on the anatomic variations, the patient can present with varying symptomatology, which can be part of paramedian thalamic syndrome. MRI including diffusion and $\mathrm{T} 2$-weighted sequences reliably demonstrates infarctions of pons, midbrain and thalamic after 12 hours from the onset of ischemia. However, sensitivity seems to be lower within the first 12 hours after ischemia and for medulla oblongata lesions ${ }^{4}$. Matheus and Castillo ${ }^{5}$ reported 3 cases of occlusion if the artery of Percheron, demonstrating symmetric thalamic and mesencephalic lesions typical for occlusion of the artery of Percheron.

Bilateral thalamic infarcts are uncommon. The paramedian thalamic region is the most commonly affected location, and usually infarcts are symmetrical and caused by multiple emboli or small artery disease. Occlusion of the artery of Percheron results in bilateral medial thalamic and rostral mesencephalic infarctions with a relative symmetrical distribution, like in this case report. Castaigne et $\mathrm{al}^{2}$ stated that, when the artery of Percheron is occluded, the thalamic infarcts are always bilateral and medial. In the setting of acute ischemic stroke that is suggestive of top of the basilar artery syndrome but no such basilar tip occlusion is found, occlusion of the artery of Percheron should be considered. In this case the presence of a large basilar tip aneurysm makes difficult to visualize and detect an occlusion of the artery of Percheron during angiography. Kostanian and $\mathrm{Cramer}^{3}$ reported a case of angiographica- 


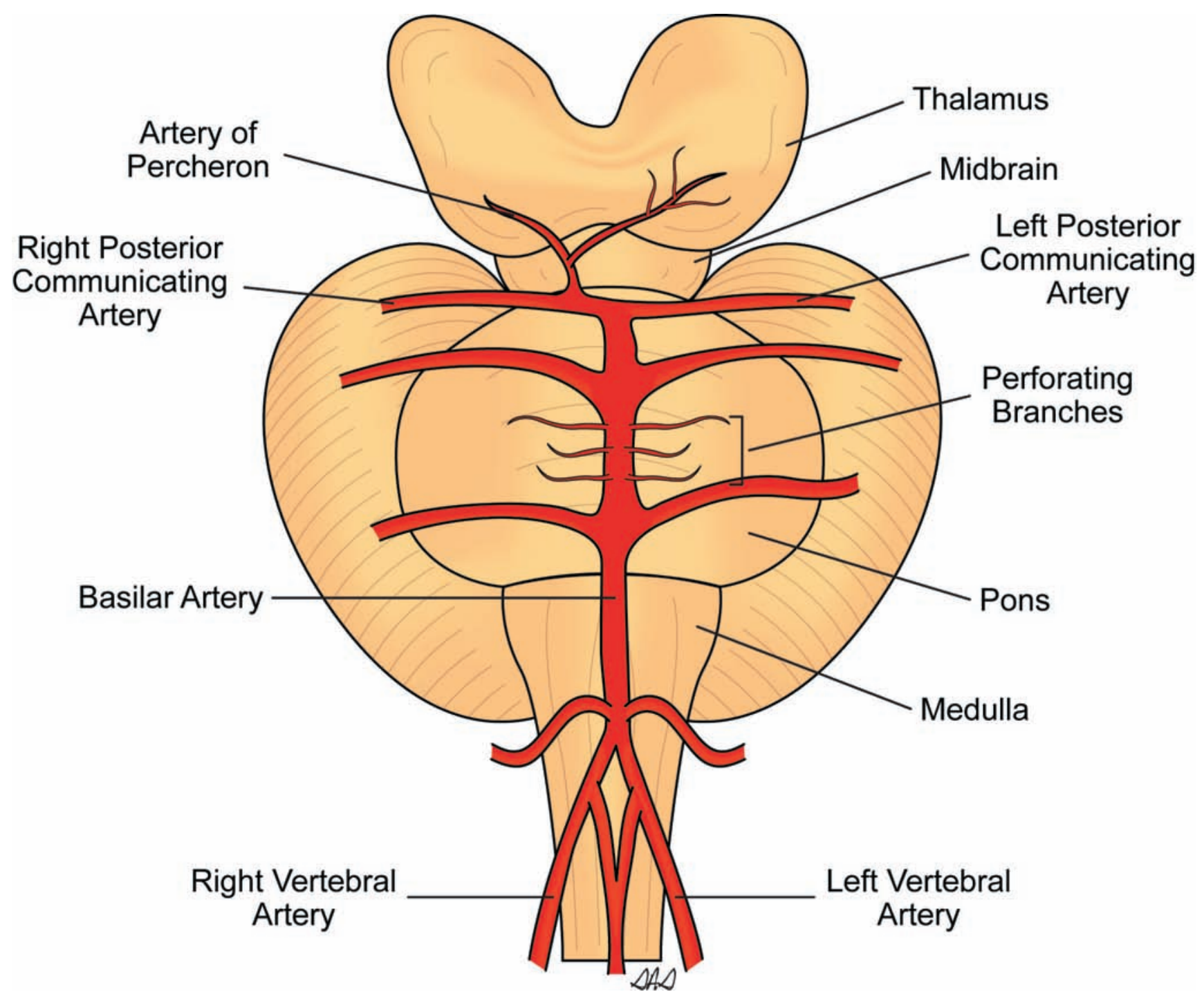

Figure 4. Artist's illustration demonstrating the Artery of Percheron as a single perforating blood vessel arising from one P1 segment.

lly diagnosed and treated acute occlusion of the artery of Percheron with super-selective thrombolysis using tissue plasminogen activator.

\section{Conclusion}

To our knowledge this is the first case report of occlusion of the unusual anatomic variant of the artery of Percheron after and elective coiling of a giant basilar tip aneurysm. Thromboembolic events related to the use of the GDC system are a common occurrence despite meticulous techniques. Diffusion-weighted MR imaging is a potentially useful tool for monitoring patients after endovascular treatment of cerebral aneurysm. These findings suggest that a presentation of acute rostral brainstem stroke accompanied by bilate- ral medial thalamic infarcts, with no basilar artery occlusion, should be suspicious for diagnosis and interventional explorations focused on potential treatment of occlusion of artery or Percheron to avoid this catastrophic complication.

\section{Acknowledgment}

We thank our graphic designer Mr. Steve Schuenke for his assistance with the illustration.

\section{References}

1. Biondi, A., Oppenheim, C., Vivas, E., et al.: Cerebral aneurysms treated by Guglielmi detachable coils: evaluation with diffusion-weighted MR imaging. AJNR 2000; 21: 957- 
963.

2. Castaigne, P., Lhermitte, F., Buge, A., Escourolle, R., Hauw, J.J., Lyon-Caen, O.: Paramedian thalamic and midbrain infarct: clinical and neuropathological study. Ann Neurol 1981; 10: 127-148.

3. Kostanian, V., Cramer, S.C.: Artery of Percheron thrombolysis. AJNR 2007; 28: 870-871.

4. Kuker, W., Weise, J., Krapf, H., Schmidt, F., Friese, S., Bahr, M.: MRI characteristics of acute and subacute brainstem and thalamic infarctions: value of T2- and diffusion-weighted sequences. J Neurol 2002; 249: 33-42.

5. Matheus, M.G., Castillo, M.: Imaging of acute bilateral paramedian thalamic and mesencephalic infarcts. AJNR 2003; 24: 2005-2008.

6. Park, H.K., Horowitz, M., Jungreis, C., et al.: Periprocedural morbidity and mortality associated with endovascular treatment of intracranial aneurysms. AJNR 2005; 26: 506-514.

7. Peluso, J.P., van Rooij, W.J., Sluzewski, M., Beute, G.N.: Coiling of basilar tip aneurysms: Results in 154 consecutive patients with emphasis on recurrent haemorrhage and re-treatment during mid- and long-term follow up. J Neurol Neurosurg Psychiatry 2008; 79: 706-711.

8. Pelz, D.M., Lownie, S.P., Fox, A.J.: Thromboembolic events associated with the treatment of cerebral aneurysms with Guglielmi detachable coils. AJNR 1998; 19: 1541-1547.

9. Percheron, G.: The anatomy of the arterial supply of the human thalamus and its use for the interpretation of the thalamic vascular pathology. Z Neurol 1973; 205: 1-13.

10. Percheron, G.: [Arteries of the human thalamus. I. Artery and polar thalamic territory of the posterior communicating artery]. Rev Neurol 1976; 132: 297-307.

11. Percheron, G.: [Arteries of the human thalamus. II. Arteries and paramedian thalamic territory of the communica- ting basilar artery]. Rev Neurol 1976; 132: 309-324.

12. Rordorf, G., Bellon, R.J., Budzik, R.E., Jr., et al.: Silent thromboembolic events associated with the treatment of unruptured cerebral aneurysms by use of Guglielmi detachable coils: prospective study applying diffusion-weighted imaging. AJNR 2001; 22: 5-10.

13. Soeda, A., Sakai, N., Sakai, H., et al.: Thromboembolic events associated with Guglielmi detachable coil embolization of asymptomatic cerebral aneurysms: evaluation of 66 consecutive cases with use of diffusion-weighted MR imaging. AJNR 2003; 24: 127-132.

14. Soeda, A., Sakai, N., Murao, K., et al.: Thromboembolic events associated with Guglielmi detachable coil embolization with use of diffusion-weighted MR imaging. Part II. Detection of the microemboli proximal to cerebral aneurysm. AJNR 2003; 24: 2035-2038.

15. Taha, M.M., Nakahara, I., Higashi, T., et al.: Endovascular embolization vs surgical clipping in treatment of cerebral aneurysms: morbidity and mortality with short-term outcome. Surg Neurol 2006; 66: 277-284.

16. van der Schaaf, I., Algra, A., Wermer, M., et al.: Endovascular coiling versus neurosurgical clipping for patients with aneurysmal subarachnoid haemorrhage. Cochrane Database Syst Rev 2005; 19: CD003085.

Rangel-Castilla, L.; Gasco, J.; Thompson, B.; Salinas, P,: Bilateral paramedian thalamic and mesencephalic infarcts after basilar tip aneurysm coiling: role of the artery of Percheron. Neurocirugía 2009; 20: 288-293.

Correspondence: Leonardo Rangel-Castilla, MD. University of Texas Medical Branch. Division of Neurosurgery. 301 University Boulevard. Galveston. Texas 77555-0517. 